\title{
Intramedullary Teratoma in an Adolescent Patient
}

\author{
Sushil Kumar ${ }^{1}$ Amit Garg ${ }^{2}$ Rohan Sinha ${ }^{1}$ Ashish Desai ${ }^{1}$
}

${ }^{1}$ Department of Neurosurgery, St. Stephens Hospital, Tis Hazari, Delhi, India

${ }^{2}$ Department of Radiology, St. Stephens Hospital, Tis Hazari, Delhi, India

Indian J Neurosurg 2017;6:232-234.
Address for correspondence Dr. Sushil Kumar, MCh, Department of Neurosurgery, St. Stephens Hospital, Tis Hazari, Delhi, India (e-mail: sushilneuro@rediffmail.com).
Abstract Keywords
- spinal cord tumor
- mature teratoma
- paraplegia

Spinal teratomas are rare spinal tumors. Most patients present with myelopathy, myeloradiculopathy, or radiculopathy. The authors describe the rare presentation of spinal teratoma with acute onset of backache followed by sudden paraplegia.

\section{Introduction}

Spinal teratomas are rare and occur more commonly in infants and children than adults. They are slow-growing tumors and present with long duration of symptoms. Our patient presented with backache of 4 days duration followed by sudden paraplegia, and because of this rare presentation, the present case is being reported.

\section{Case Report}

A 15-year-old girl developed backache mild to moderate in intensity lasting for 4 days and then developed sudden weakness of both lower limbs and inability to pass urine. Indwelling catheter was put in and she reported to our hospital 25 days later for further treatment. There was no history of trauma and fever. On examination higher functions and upper limbs were normal. There was hypotonia in lower limbs, power was grade 0 at all joints, and deep tendon reflexes were absent. Sensations were absent up to umbilicus. There was no spinal tenderness and deformity. Pressure sore was present over heels and indwelling catheter was in situ. Magnetic resonance imaging (MRI) revealed expansion of the cord with hyperintense rim surrounded by hypointensity (hemosiderin) (-Fig. 1a). Posterior aspect showed hyperintense fat ( $\mathbf{- F i g}$. 1b). Postcontrast axial image showed hyperintense enhancement with fatty component posteriorly ( - Fig. 1c). Laminectomy revealed expansion of

received

December 30, 2015

accepted after revision

February 10, 2016

published online

May 9, 2017
DOI https://doi.org/

10.1055/s-0036-1584587. ISSN 2277-954X. the cord and myelotomy revealed altered blood and very well-delineated pale soft tissue mass with smooth surface (-Fig. 2a). Cut surface showed grayish to yellow appearance, which, on histopathology, revealed that the capsule was composed of columnar and stratified squamous epithelium. There were mucus glands filled with the mucin, nerve fibers, and glial cells(-Fig. 2b), adipose tissue and fibrous tissue, patchy congestion, hemorrhage, and infiltration by foamy macrophages with brown pigment (-Fig. 2c). Histologic analysis demonstrated a mature teratoma with components of all three germ layers: ectoderm, mesoderm, and endoderm. The patient was discharged on 10th post operative day without any improvement. She never reported for follow-up. Letters sent to her on the address have been returned with comment of inadequate address.

\section{Discussion}

Willis defined teratoma as a malformation composed of multiple tissues foreign to their location and lacking organ specificity. ${ }^{1}$ Spinal teratoma is very rare and accounts for 0.2 to $0.5 \%$ of all spinal cord tumors. ${ }^{2}$ Teratoma involves males more often than females, but our patient was female. ${ }^{3}$ Most patients present with myelopathy, myeloradiculopathy, or radiculopathy, depending on the location of tumor. In our patient acute onset could be attributed to venous infarction caused by pressure of the tumor to the draining vessels leading to venous infarct of the cord. There is predilection of

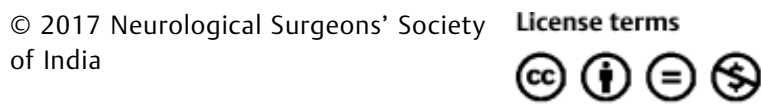




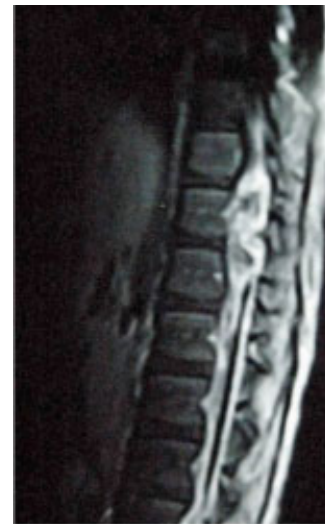

a

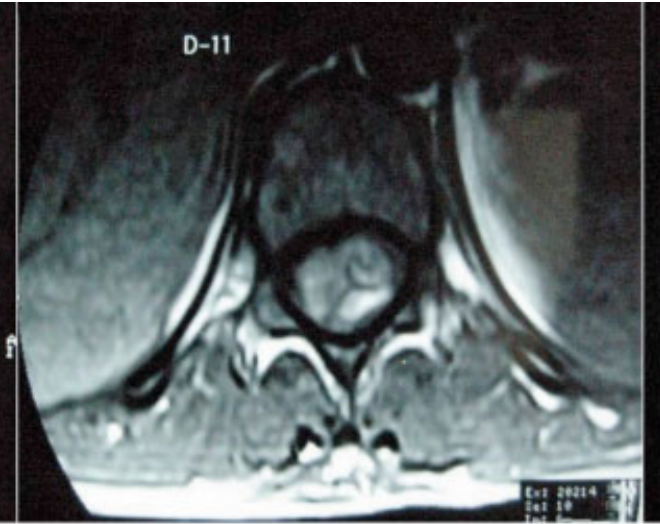

b

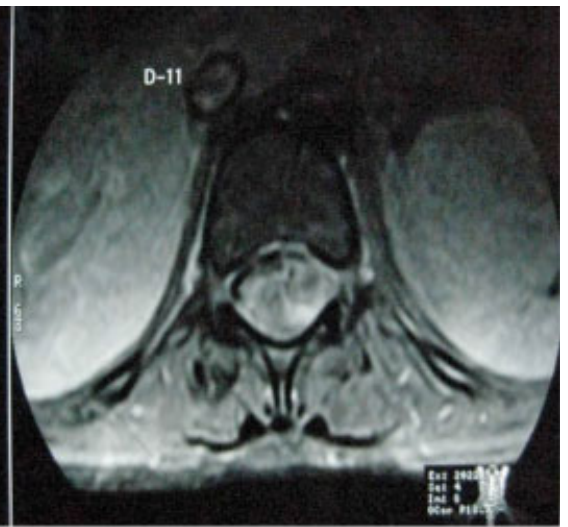

C

Fig. 1 (a) Sagittal STIR image showing hyperintense rim surrounded by hypointensity (hemosiderin). (b) Axial T1 image showing expansile lesion of the cord with hypointense rim. The posterior aspect shows hyperintense content (Fat). (c) Postcontrast axial T1 (Fat sat.) showing heterogeneous enhancement with fatty component posteriorly.

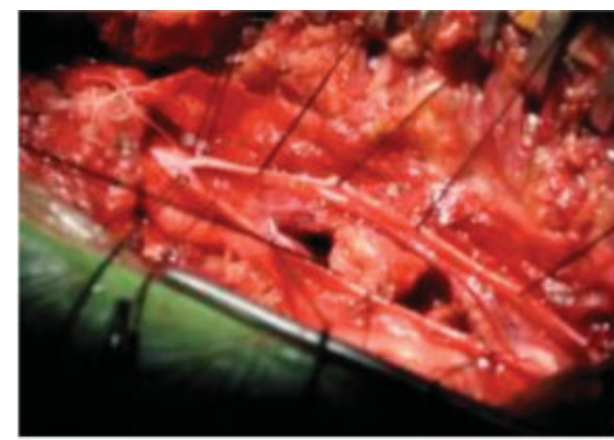

a

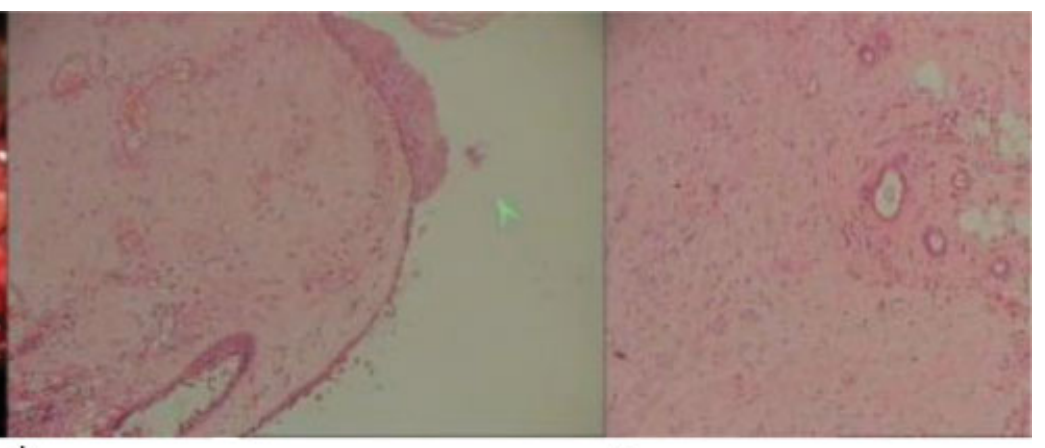

C

Fig. 2 (a) Per-operative photograph showing well-defined intramedullary tumor. (b and c) Cyst wall lined by pseudostratified columnar epithelium, nerve bundle, glands, and fat cells.

thoracic spine and conus medullaris. ${ }^{4}$ Some patients have congenital skin abnormalities such as dermal sinus, tuff of hair, nevi, and vertebral anomalies at the same level. Our patient had none of the associated cutaneous or osseous anomalies. Water and Kleinert ${ }^{5}$ classified central nervous system (CNS) teratoma into three groups: mature, immature, and malignant type depending on the degree of differentiation. Mature teratoma is composed of fully differentiated adult-type tissue elements representative of the three germ layers ${ }^{2}$; however, the presence of only two germinal layer elements does not rule out the diagnosis as derivatives of one or two layers may overgrow the other. ${ }^{6}$

Plain X-ray often shows erosion of vertebral bodies and widening of interpedicular space with or without associated vertebral anomalies such as spina bifida, vertebral body fusion, and diastematomyelia at the same level of teratoma, although none of these were seen in our case.

Preoperative diagnosis of spinal teratoma is not easy .The MRI features cannot determine with certainty the diagnosis of teratoma; however, presence of fat, solid, and cystic areas with heterogeneous enhancement on postcontrast T1weighted image may suggest the possibility of teratoma.
Radical removal of the teratoma along with its capsule should be the aim of the surgery as demonstrated by our case as well. However, subtotal resection has also been advocated by some authors so as to avoid an increase in neurologic damage because of firm adhesions with cord and roots and recurrence rate being similar for total and subtotal resection over a long period of time., ${ }^{3,7}$ In our case we could remove the tumor completely because of surrounding softened cord tissue.

Macroscopically teratoma has cystic and solid components with a capsule that is adherent to spinal cord parenchyma. Backache and sudden weakness in our patient occurred because of the hemorrhage around the tumor that has not been reported so far in the literature.

Three hypotheses have been suggested as regard to their origin. According to the most accepted theory, teratoma arises from primordial germ cells misplaced into the dorsal midline from yolk sac to the gonadal ridges. ${ }^{8}$

\section{Contribution}

All the authors have contributed to the collection of data, clinical aspect, and formatting for the publication, as well as, designed and approved the study. 


\section{Intramedullary Teratoma in an Adolescent Patient Kumar et al.}

Conflict of interest

None.

\section{Funding}

No funding received.

\section{References}

1 Willis RA. Pathology of Tumors. London, UK: Butterworth and Co.; 1948:940-988

2 Ak H, Ulu MO, Sar M, Albayram S, Aydin S, Uzan M. Adult intramedullary mature teratoma of the spinal cord: review of the literature illustrated with an unusual example. Acta Neurochir (Wien) 2006;148(6):663-669, discussion 669

3 Sharma MC, Aggarwal M, Ralte AM, et al. Clinicopathological study of spinal teratomas. A series of 10 case. J Neurosurg Sci
2003;47(2):95-100, discussion 100

4 Kahilogullari G, Erdem A, Heper AO, Erden E. Intramedullary mature cystic teratoma of the conus medullaris. A case report. J Neurosurg Sci 2006;50(2):55-58

5 Walter GF, Kleinert R. Dysontogenetic brain tumours-proposal for an improved classification. Neuropathol Appl Neurobiol 1987;13(4):273-287

6 Nonomura Y, Miyamoto K, Wada E, et al. Intramedullary teratoma of the spine: report of two adult cases. Spinal Cord 2002;40(1):40-43

7 Allsopp G, Sgouros S, Barber P, Walsh AR. Spinal teratoma: is there a place for adjuvant treatment? Two cases and a review of the literature. Br J Neurosurg 2000;14(5):482-488

8 al-Sarraj ST, Parmar D, Dean AF, Phookun G, Bridges LR. Clinicopathological study of seven cases of spinal cord teratoma: a possible germ cell origin. Histopathology 1998; 32(1):51-56 